\title{
New Risk Measure and Idiosyncratic Risk in Taiwan Stock Market
}

\author{
Yin-Ching Jan ${ }^{1}$, Su-Ling Chiu ${ }^{1} \&$ Jerry M. C. Wang ${ }^{2}$ \\ ${ }^{1}$ National Chin-Yi University of Technology, Taiwan \\ ${ }^{2}$ National Taichung University of Science and Technology, Taiwan \\ Correspondence: Yin-Ching Jan, National Chin-Yi University of Technology, Taiwan. E-mail: \\ jan511@mail.ncut.edu.tw
}

Received: February 22, 2013

Accepted: March 18, 2013

Online Published: April 8, 2013

doi:10.5430/ijfr.v4n2p77

URL: http://dx.doi.org/10.5430/ijfr.v4n2p77

\begin{abstract}
Under the model developed by Merton (1987), the idiosyncratic risk would be important to explain the expected stock return. We follow the approach of Daniel and Titman (1998), and use the risk measure developed by Jan and Wang (2012) to examine whether idiosyncratic risk can play an important role in explaining the expected return in Taiwan stock market. We find that beta can't explain the expected return, and that idiosyncratic risk has a positive relation to expected returns for stocks with smaller beta portfolio. We also explore a weak evidence of the positive relationship between idiosyncratic risk and expected return for size-sorted portfolio.
\end{abstract}

Keywords: asset pricing model, martingale, idiosyncratic risk, Taiwan stock market

\section{Introduction}

The relation between risk and return always puzzles the academics and practitioners. If asset pricing model can explain expected asset's return properly, then the investors can easily allocate their fund into diversify assets based on the degree of risk aversion. However, the risk/return relation doesn't come to consensus for the academics and practitioners.

In addition, investors may not hold diversified portfolios. Goetzmann and Kumar (2004) show that more than half of the U.S. investor portfolios contain less than three stocks, based on a sample of more than 62,000 household investors in the period of 1991 to 1996 . Therefore, other factors, beside the betas of asset, may have the power to explain the expected return. The study of Merton (1987) has stated that idiosyncratic risk should be priced when investors hold sub-optimally diversified portfolios.

The role of idiosyncratic risk in explaining the relationship between risk and return has been debated in academics and practitioners. Among others, Xu and Malkiel (2004) discover that idiosyncratic volatility is more powerful in explaining the cross-section of expected returns, even after controlling for firm size and book-to-market equity. However, Ang, et.al (2006) find that idiosyncratic volatility is negatively related to expected return. Jiang, Xu, and Yao (2006) argue that the negative relation between idiosyncratic volatility and expected return is related to corporate selective disclosure, and is stronger among stocks with a less sophisticated investor base. The work of Boehme, et al. (2006) confirms the model of Merton (1987), which predicts the positive relation between idiosyncratic risk and expected returns. $\mathrm{Fu}(2009)$ finds a significantly positive relation between the estimated conditional idiosyncratic volatilities and expected returns. Miralles-Marcelo, Miralles-Quirós, and Miralles-Quirós (2012) propose an asset pricing including idiosyncratic risk as a source of another kind of systematic risk un-captured by beta. They find that idiosyncratic volatility has a significant and positive relation to future stock market returns. Moreover, Cao and Han (2012) find that delta-hedged equity option return decreases monotonically with an increase in the idiosyncratic volatility of the underlying stock.

How to measure the idiosyncratic risk would be an important when we examine whether idiosyncratic risk is priced. Bali and Cakici (2008) have discovered that the ways used to estimate idiosyncratic volatility play critical roles in determining the existence and significance of a relation between idiosyncratic risk and the cross section of expected returns. However, there are lots of various measurements on investment risk. See, for example, the reviews of Balzer (1995) and Nawrocki (1999). To obtain a single objective risk measure, we need an objective risk benchmark. In this study, we apply a new risk measure developed by Jan and Wang (2012) to avoid a benchmark return to compute the investment risk. The new measurement is based on the property of martingale. The expectation of next day return is 
today return. Therefore, the best expectation of next return is today return.

There may be more under-diversified investors in the Taiwan Stock Market. This would lead to some factors other than beta can explain the relationship between risk and return. See, e.g., Huang (1997), Sheu, Wu, and Ku (1998), and Lin and Wang (2003). In order to clarify whether idiosyncratic risk is priced in the Taiwan Stock Market, we follow the approach of Daniel and Titman (1998) to examine whether portfolios formed by different idiosyncratic risks have different expected returns.

We find that beta can't explain the expected return in the Taiwan stock market, and that idiosyncratic risk has a positive relation to expected returns for stocks with smaller beta. We also explore the existence of size effect, and find a weak evidence of the positive relationship between idiosyncratic risk and expected return for size-sorted portfolios.

The remainder of the article is organized as follows. Next Section presents the data and methodology. Section 3 shows the measurement of idiosyncratic risk. Section 4 shows the empirical results. Finally, Section 4 has concluding remarks.

\section{Methodology}

We follow the approach of Daniel and Titman (1998) to test whether portfolio formed by different idiosyncratic risk have different expected return. The sample comes from Taiwan Economic Journal from June 1979 to June 2012. The sample contains 2201 stocks. The risk-free rate is the one-month deposit rate at the First Commercial Bank. The testing procedure is as follows:

\subsection{Computing Betas of Asset Pricing Model}

The asset pricing models we use are Capital Asset Pricing Model (CAPM). The previous 36 monthly stock's returns are used to compute the beta for the 37th month. By rolling this procedure, we can get the monthly betas for each stock from June 1982 to June 2012. We delete stocks with delisting, listing period less than 36 month, or stocks which have not traded continuously. The remaining stocks included in our sample are 1673.

\subsection{Calculating the Error Term}

Inserting each monthly beta into CAPM, we can get the monthly error term for each stock. For example, the beta, stock return, market return, and risk-free rate of 37th month are inserted into CAPM to get the 37th month error term for each stock. By rolling this procedure, we get the monthly error term for each stock from June 1982 to June 2012.

\subsection{Calculating the Risk Measure}

We use 36 monthly error terms to calculate idiosyncratic risk measure. For instance, we apply the error term of the 37th month to 72th month to calculate the idiosyncratic risk measures for the 72th month. By rolling this procedure, we can compute all of the idiosyncratic risk measures for each stock form June 1985 to June 2012.

\subsection{Forming Portfolios}

We first rank all stocks by their beta at June of year $\mathrm{t}$, and form five portfolios based on these ranking from small to large. Then, we rank each beta portfolio by their idiosyncratic risk at June of year $t$, and separate each beta portfolio into five portfolios from small to large. By holding the portfolios from July of year $t+1$ to June of year $t+1$, we compute the weighted average monthly return for each portfolio.

\subsection{Performance Comparison}

If the idiosyncratic risk isn't priced, the different idiosyncratic risk sub-portfolios contained in the same beta portfolio will have the same risk-adjusted return. As a result, we can compare whether risk-adjusted returns of the five sub-portfolios contained in the same beta portfolio are equal. We apply Jensen's alpha $(\alpha)$ to calculate risk-adjusted return. The comparing period is from July 1988 to June 2012, because the number of stocks contained in each sub-portfolios are two small in the early period.

\section{Risk Measure}

The idiosyncratic risk measure comes from the work of Jan and Wang (2012). Jan and Wang use of the property of martingale to predict return of next period. That is, the expectation of return of next period is today return instead of average return. They adjust the conventional semi-variance by adding martingale semi-variance. The martingale variance ( $M V A R)$ is calculated as follows: 


$$
\begin{aligned}
\operatorname{MVAR}(R) & =\frac{\sum_{t=1}^{T}\left(R_{t}-R_{t-1}\right)^{2}}{T} \\
& =\frac{2\left\{\left(\sum_{\mathrm{t}=1}^{\mathrm{T}} \mathrm{R}_{\mathrm{t}}^{2}-E(R)^{2}\right)-\left(\sum_{t=1}^{T} R_{t} R_{t-1}-E(R)^{2}\right)\right\}}{T} \\
& =2\left\{\operatorname{VAR}(R)-\operatorname{COV}\left(R_{t}, R_{t-1}\right)\right\}
\end{aligned}
$$

where $R_{t}$ denotes an asset return at time $t, T$ is sample size, and $E(\bullet)$ represents expectation operator. VAR and $\mathrm{COV}$ are traditional variance and covariance operators, respectively.

From (1), we see that the martingale variance is computed by the variance minus autocorrelation, and is different from the work of Goyal and Santa-Clara (2003) in the second term, where theirs is positive. Jan and Wang (2012) have demonstrated why including martingale variance in superior to the ordinary variance.

The martingale variance can capture the time series autocorrelation pattern, but may not be an adequate risk measure. This is because the martingale variance can't distinguish the upward trend with downward trend. However, return with downward trend would be thought to be riskier for most investor. The problem can be solved by martingale semi-variance ( $M S A V R)$, which can be written as:

$$
\operatorname{MSVAR}(R)=\frac{\sum_{t=1}^{T}\left\{\operatorname{Min}\left(0, R_{t}-R_{t-1}\right)\right\}^{2}}{T}
$$

where $\operatorname{Min}(\bullet, \bullet)$ is minimum operator.

The martingale semi-variance can be thought as relative semi-variance introduced by Balzer (1995). Nevertheless, Jan and Wang (2012) use past return as the time-varying return benchmark. As a result, the idiosyncratic risk measure (IRM) is computed as follows:

$$
I R M=\left[\frac{\sum_{t=1}^{T}\left\{\operatorname{Min}\left(0, R_{t}-\bar{R}\right)\right\}^{2}}{T}+\frac{\sum_{t=1}^{T}\left\{\operatorname{Min}\left(0, R_{t}-R_{t-1}\right)\right\}^{2}}{T}\right]^{0.5}
$$

where $\bar{R}$ is average return.

\section{Empirical Results}

The significance impact of the idiosyncratic risk on the expected return is determined by examining whether each five beta sub-portfolios have the same risk-adjusted return. We apply Jensen's alpha $(\alpha)$ to calculate risk-adjusted return.

Panel A of Table 1 shows the average return, standard deviation, and Jensen's $\alpha$ for the five portfolios sorted by beta. We see that the largest average return and Jensen's $\alpha$ appears in the smallest beta portfolio, and the third portfolio has smallest average return and Jensen's $\alpha$. The result doesn't support to the expectation of CAPM, which states that the smaller the beta is, the smallest the average return is.

Panel B of Table 1 displays the average return, standard deviation, and Jensen's $\alpha$ for the 25 beta and idiosyncratic risk sorted portfolios. For the least two beta portfolios, the sorting of the average return and Jensen's $\alpha$ is coincided with the sorting of idiosyncratic risk, implying that the largest the idiosyncratic risk is, the largest the average return and Jensen's $\alpha$ are. For the third beta portfolio, the largest average return and Jensen's $\alpha$ is appeared in the largest idiosyncratic risk category. The smallest average return and Jensen's $\alpha$ are appeared in the second idiosyncratic risk portfolio. For the fourth beta portfolio, the average return and Jensen's $\alpha$ of the fourth idiosyncratic risk portfolio are smaller than those of second and third portfolios. For the largest beta portfolio, the average return and Jensen's $\alpha$. of the largest idiosyncratic risk portfolio are smaller than those of third and fourth portfolios. For the three larger beta portfolios, the ordering of Jensen's $\alpha$ isn't accord with the ordering of the idiosyncratic risk. Nevertheless, the 
average return and Jensen's $\alpha$ of portfolios with larger idiosyncratic risk are almost larger than those of portfolios with smaller idiosyncratic risk. The results imply that idiosyncratic risk plays an important role in explaining expected return.

This study also examined whether size-sorted portfolios with different idiosyncratic risk have the same risk-adjusted return. Panel A of Table 2 displays the average return, standard deviation, and Jensen's $\alpha$ for the five portfolios sorted by market value. The result shows that the smaller the size is, the larger the average return and Jensen's $\alpha$ are, implying that the size effect is still existed in the market.

Table 1. Summary statistics and the Jensen's $\alpha$ for the beta-sorted portfolios

\begin{tabular}{|c|c|c|c|c|c|c|}
\hline \multicolumn{7}{|c|}{ Panel A. Sorting by beta only } \\
\hline & \multirow{4}{*}{$\begin{array}{c}\text { Mean } \\
\text { S.D } \\
\alpha .\end{array}$} & Smallest & 2 & beta & 4 & Largest \\
\hline & & 1.712 & 1.562 & 1.346 & 1.647 & 1.582 \\
\hline & & 9.557 & 10.027 & 10.591 & 12.115 & 12.430 \\
\hline & & 1.133 & 0.969 & 0.733 & 0.981 & 0.900 \\
\hline \multicolumn{7}{|c|}{ Panel B. Sorting by beta and idiosyncratic risk } \\
\hline \multirow{4}{*}{ Smallest } & & Smallest & 2 & Idiosyncratic risk & 4 & Largest \\
\hline & Mean & 1.429 & 1.516 & 2.174 & 2.539 & 2.473 \\
\hline & S.D & 9.644 & 9.306 & 12.354 & 14.791 & 13.084 \\
\hline & a. & 0.883 & 0.975 & 1.583 & 1.867 & 1.860 \\
\hline \multirow{3}{*}{2} & Mean & 1.014 & 1.332 & 1.582 & 1.898 & 2.670 \\
\hline & S.D & 9.805 & 10.751 & 12.145 & 12.219 & 14.452 \\
\hline & $\alpha$ & 0.453 & 0.741 & 0.948 & 1.276 & 2.018 \\
\hline \multirow{3}{*}{ beta } & Mean & 1.315 & 1.259 & 1.471 & 1.440 & 2.095 \\
\hline & S.D & 10.953 & 10.932 & 12.804 & 14.018 & 14.424 \\
\hline & 0 & 0.711 & 0.657 & 0.819 & 0.781 & 1.437 \\
\hline \multirow{3}{*}{4} & Mean & 1.361 & 1.781 & 1.947 & 1.455 & 2.681 \\
\hline & S.D & 12.790 & 12.288 & 13.017 & 13.665 & 16.672 \\
\hline & $\alpha$ & 0.696 & 1.138 & 1.286 & 0.803 & 1.980 \\
\hline \multirow{3}{*}{ Largest } & Mean & 0.997 & 1.114 & 2.299 & 2.581 & 2.058 \\
\hline & S.D & 11.808 & 13.454 & 14.380 & 15.101 & 14.972 \\
\hline & $\alpha$ & 0.349 & 0.423 & 1.614 & 1.895 & 1.361 \\
\hline
\end{tabular}

Mean denotes weighted average monthly return, S.D is standard deviation, and $\alpha$ represents Jensen's alpha. All of the figures are displayed in percent.

Panel B of Table 2 shows the average return, standard deviation, and Jensen's $\alpha$ for the 25 size and idiosyncratic risk sorted portfolios. For the least two size portfolios, the largest average return and Jensen's $\alpha$ are appeared in the third portfolio, while the smallest average return and Jensen's $\alpha$ are appeared in the first portfolio. For the third and fourth size portfolios, the largest average return and Jensen's $\alpha$ are appeared in the fifth and third idiosyncratic risk category, respectively. The smallest average return and Jensen's $\alpha$ are appeared in the first idiosyncratic risk portfolio. For the largest size portfolio, the largest average return and Jensen's $\alpha$ are in the fourth idiosyncratic risk portfolio, while the smallest average return and Jensen's $\alpha$ are in the first portfolio. The average return and Jensen's $\alpha$ of portfolios with larger idiosyncratic risk are almost larger than those of portfolios with smaller idiosyncratic risk, although the ordering of Jensen's $\alpha$ isn't accord with the ordering of the idiosyncratic risk. The results are similar to those of beta-sorted portfolio. 
Table 2. Summary statistics and the Jensen's $\alpha$ for the size-sorted portfolios

\begin{tabular}{|c|c|c|c|c|c|c|}
\hline \multicolumn{7}{|c|}{ Panel A. Sorting by size only } \\
\hline & & Smallest & 2 & beta & 4 & Largest \\
\hline & Mean & 3.263 & 2.549 & 2.118 & 1.937 & 1.478 \\
\hline & S.D & 12.241 & 11.879 & 10.831 & 10.371 & 10.500 \\
\hline & $\alpha$ & 2.645 & 1.917 & 1.510 & 1.317 & 0.842 \\
\hline \multicolumn{7}{|c|}{ Panel B. Sorting by size and idiosyncratic risk } \\
\hline \multirow{4}{*}{ Smallest } & & Smallest & 2 & Idiosyncratic risk & 4 & Largest \\
\hline & Mean & 2.598 & 2.887 & 3.797 & 3.208 & 3.018 \\
\hline & S.D & 12.711 & 14.238 & 15.657 & 11.091 & 12.753 \\
\hline & $\alpha$ & 1.983 & 2.238 & 3.133 & 2.661 & 2.402 \\
\hline \multirow{3}{*}{2} & Mean & 2.152 & 2.471 & 2.735 & 2.396 & 2.379 \\
\hline & S.D & 11.967 & 12.985 & 14.075 & 12.567 & 12.176 \\
\hline & $\alpha$ & 1.539 & 1.817 & 2.084 & 1.759 & 1.763 \\
\hline \multirow{3}{*}{ size } & Mean & 1.680 & 1.940 & 1.861 & 2.334 & 2.098 \\
\hline & S.D & 10.312 & 11.497 & 12.305 & 12.216 & 11.795 \\
\hline & $\alpha$ & 1.099 & 1.329 & 1.232 & 1.735 & 1.477 \\
\hline \multirow{3}{*}{4} & Mean & 1.301 & 1.707 & 2.220 & 1.742 & 2.133 \\
\hline & S.D & 9.178 & 10.729 & 11.591 & 12.369 & 11.659 \\
\hline & $\alpha$ & 0.743 & 1.101 & 1.576 & 1.081 & 1.496 \\
\hline \multirow{3}{*}{ Largest } & Mean & 1.068 & 1.258 & 1.204 & 1.768 & 1.386 \\
\hline & S.D & 9.135 & 10.049 & 11.855 & 12.451 & 11.509 \\
\hline & $\alpha$ & 0.498 & 0.652 & 0.539 & 1.089 & 0.748 \\
\hline
\end{tabular}

Mean denotes weighted average monthly return, S.D is standard deviation, and $\alpha$ represents Jensen's alpha. All of the figures are displayed in percent.

\section{Conclusion}

Under the framework of the CAPM, idiosyncratic risk should not play a role in risk/return relationship as long as the investors hold diversified portfolio. However, researchers have found that most investors do not hold the diversified portfolio. There may be more under-diversified investors in the Taiwan Stock Market. Merton (1987) has developed an asset pricing model with a risk premium depends on the relationship between the idiosyncratic risk. In this paper, we examine whether idiosyncratic risk can play an important role in explaining the expected return in the Taiwan stock market.

We follow the approach of Daniel and Titman (1998), and use the risk measure developed by Jan and Wang (2012). We find that beta can't explain the expected return in the Taiwan stock market, and that idiosyncratic risk has a positive relation to expected returns for stocks with smaller beta. We also explore a weak evidence of the positive relationship between idiosyncratic risk and expected return for size-sorted portfolio. 


\section{References}

Ang, A., Hodrick, R.J., Xing, Y., \& Zhang, Y. (2006). The cross-section of volatility and expected returns. Journal of Finance, 61(1), 259-299. http://dx.doi.org/10.1111/j.1540-6261.2006.00836.x

Bali, T. G., \& Cakici, N. (2008). Idiosyncratic Volatility and the Cross Section of Expected Returns, Journal of Financial and Quantitative Analysis, 43(1), 29-58. http://dx.doi.org/10.1017/S002210900000274X

Balzer, L. (1994). Measuring Investment Risk: A Review. Journal of Investing, 3(3), 47-58. http://dx.doi.org/10.3905/joi.3.3.47

Boehme, R.D., Danielsen B.R., Kumar, P., \& Sorescu, S.M. (2009). Idiosyncratic risk and the cross-section of stock returns: Merton (1987) meets Miller. Journal of Financial Markets, 12, 438-468. http://dx.doi.org/10.1016/j.finmar.2009.01.004

Campbell, J., Lettau, M., Malkiel, B., \& Xu, Y. (2001). Have individual stocks become more volatile? An empirical exploration of idiosyncratic risk. Journal of Finance, 56(1), 1-43. http://dx.doi.org/10.1111/0022-1082.00318

Cao, J., \& Han, B. (2012). Cross-Section of Option Returns and Idiosyncratic Stock Volatility, McCombs Research AFA 2012 Chicago Meetings Paper. Retrieved from http://ssrn.com/abstract=1786607

Fu, F. (2009). Idiosyncratic Risk and the Cross-Section of Expected Stock Returns. Journal of Financial Economics, 91(1), 24-37. http://dx.doi.org/10.1016/j.jfineco.2008.02.003

Goetzmann, W., \& Kumar, A. (2004). Why do individual investors hold under-diversified portfolios? Review of Finance, 12(3), 433-463. http://dx.doi.org/10.1093/rof/rfn005

Goyal, A., \& Santa-Clara P. (2003). Idiosyncratic risk matters! Journal of Finance, 58(3), 975-1008. http://dx.doi.org/10.1111/1540-6261.00555

Huang, Y-S. (1997). The size anomaly on the Taiwan Stock Exchange. Applied Economics Letters, 4(1), 7-12. http://dx.doi.org/10.1080/758521823

Jan, Y-C., \& Wang, J. M. C. (2012). A note on idiosyncratic risk measure. Journal of Money, Investment and Banking, $25,119-123$.

Jiang, G., Xu, D., \& Yao, T. (2006). The information content of idiosyncratic volatility. Journal of Financial Quantitative Analysis, 44(1), 1-28. http://dx.doi.org/10.1017/S0022109009090073

Lin, B-H., \&Wang, J. M. C. (2003). Systematic skewness in asset pricing: an empirical examination of the Taiwan stock market. Applied Economics, 35(1), 1877-1887. http://dx.doi.org/10.1080/00036840310001628044

Merton, R. (1987). A simple model of capital market equilibrium with incomplete information. Journal of Finance, 42, 483-510. http://dx.doi.org/10.1111/j.1540-6261.1987.tb04565.x

Miralles-Marcelo, J. L., Miralles-Quirós, M., \& Miralles-Quirós, J. L. (2012). Asset pricing with idiosyncratic risk: The Spanish case. International Review of Economics and Finance, 21, 261-271. http://dx.doi.org/10.1016/j.iref.2011.07.004

Nawrocko, D. (1999). A brief history of downside risk measures. Journal of Investing, 8(3), 9-25. http://dx.doi.org/10.3905/joi.1999.319365

Sheu, H-J, Wu, S., \& Ku, K-P. (1998). Cross-sectional relationships between stock returns and market beta, trading volume, and sales-to-price in Taiwan. International Review of Financial Analysis, 7(1), 1-18. http://dx.doi.org/10.1016/S1057-5219(99)80035-0

Xu, Y., \& Malkiel, B. (2004). Idiosyncratic Risk and Security Returns. AFA 2001 New Orleans Meetings, May, Retrieved from http://ssrn.com/abstract $=255303$

Note

Note 1 . The procedure can't prevent our study from survivorship bias. 